\title{
Methods of Dyes Removal from Aqueous Environment
}

\author{
Agnieszka Bożęcka1", Monika Orlof-Naturalna', Monika Kopeć1 \\ 1 Faculty of Civil Engineering and Resource Management, AGH University of Science and Technology, \\ Al. Mickiewicza 30, 30-059 Krakow, Poland \\ * Corresponding author's e-mail: gala@agh.edu.pl
}

\begin{abstract}
In this paper, selected methods of dyes removal from water environment were discussed, with particular attention to the adsorption method. A literature review of the latest scientific research on colour impurities removal with the use of various types of adsorbents was presented. The efficiency of the methylene blue removal process, with use of selected natural sorbents and activated carbons, was tested. The competitiveness of natural sorbents was shown. It was confirmed that these materials are efficient in removing coloured compounds from aqueous solutions.
\end{abstract}

Keywords: dyes, adsorption, wastewater.

\section{INTRODUCTION}

Dyes are one of the most common pollutants in water environment. It is related to their use in various industries, including textiles, cosmetics, food, etc. The colour compounds present in industrial wastewater are dangerous due to their toxicity, low biodegradability and intense colour. Their presence in surface waters significantly affects the entire ecosystem, among others, by interfering with the photosynthesis process and having a direct, harmful effect on living organisms. These compounds are also harmful to the human body, causing various diseases.

For this reason, it is necessary to efficiently treat the wastewater containing dyes. Various processes are used for this purpose, including chemical oxidation, precipitation and coagulation, biological treatment, membrane techniques and adsorption on activated carbons [Pieczykolan et al., 2020]. However, many of classical methods are not sufficiently efficient in removing these pollutants, mainly due to different quantitative and qualitative composition of treated wastewater. Additionally, some of these methods are expensive; therefore, it has become necessary to search for cheaper and more efficient technologies.

The aim of this study was to present the methods of dye removal from water environment, with particular emphasis on the adsorption method. Due to its advantages and a large variety of materials that can be used, this method gives hope for the introduction of much more efficient and cheaper adsorbents to treatment of industrial wastewater. In the experimental part of this work, the efficiency of the methylene blue removal process, with use of selected natural sorbents, was examined and compared with the efficiency of activated carbons.

\section{Characteristics of dyes}

Dyes are chemical compounds that are characterized by their ability for intense absorption and conversion of electromagnetic radiation energy in visible, near ultraviolet and near infrared light ranges. They are used to transfer abovementioned properties to other substances. On contact with various materials, such as: natural and artificial fibres, paper or others, they bind with them in a permanent manner, causing them to colour. The practical use of dyes depends on the conversion type of absorbed energy. These compounds should be resistant to sunlight, water and other factors resulting from use of coloured products [Kwiecień, 2014].

Dyes were introduced gradually over the years and became more common. Their quantity 
has increased significantly, which led to the publication of various criteria for their classification. They were based on the name, colour or chemical structure of these compounds. It was only in 1924 that all these classifications were replaced by the Colour Index (C.I.), which was quickly accepted by all countries producing dyes [Kwiecień, 2014].

Currently, this catalogue classifies dyes according to their structure (chemical classification is useful for chemists, for whom the information on synthesis methods and structure of dyes is important) and their application (technical classification is intended for the users who expect the information about commercial products, resistance properties of dyes, etc.) [Kwiecień, 2014].

Nowadays, dyes are used in almost every field of industry. Durability of dyeing and a wide range of colours offered by the industry have influence on chemical stability and visual features of the products. This increases their market demand and customer interest. This, in turn, is associated with greater quantity of produced and used dyes [Kliś, 2019].

These compounds are used in many industries, such as the tanning, food, paper and cosmetics industries. Almost all manufactured goods are dyed, from textiles, artificial and natural materials, varnishes, paints to food and cosmetics. Special dyes are even produced for the purposes of photography, laser techniques or medical diagnostics, as well as other areas, seemingly distant from the chemical technology [Kliś, 2019, MuszPomorska and Widomski, 2019].

\section{Effect of dyes on water environment}

As previously mentioned, various shades, availability of raw materials caused that coloured substances began to dominate in the industry. However, this intensive development of dyes, pigments and paints manufacturing, contributed to formation of various types of waste, which, infiltrating into the natural environment, pose a serious threat to aquatic ecosystems [Kusumawati et al., 2020].

Most dyes have a negative effect on the living organisms found in natural waters. Their indirect influence is to change the colour of the waters. The discharge of sewage containing dyes causes a noticeable change in this parameter. The visual characteristics of the waters deteriorate. There is also a change in the chemical composition of the water. The colouration caused by the discharge of sewage into water reservoirs, e.g., from a dye house or a textile printing house, significantly reduces light transmittance. The risk of oxygen deficiency increases then, because the photosynthesis process carried out by algae and plants is inhibited. The self-purification capacity of water is also disturbed. All this leads to deterioration of living conditions for fish and aquatic plants. The change of these factors makes it difficult for living organisms to adapt to new environment [Guan et al., 2020].

The direct impact of dyes on living organisms is related to their toxic, carcinogenic and mutagenic properties. Colour compounds are also hardly biodegradable [Kusumawati et al., 2020]. Some aniline dyes, present in water, even in small quantities, can accumulate in fish organisms, changing the colour of meat itself and contributing to many diseases as well as their deaths. More harmful are the dyes that affect fish food plankton. Even a small concentration of them has a lethal effect on algae. These dyes include, among others: methyl blue, diamond green and carbon black BT [Okoniewska, 2016].

\section{Methods for removal of dyes from wastewater}

The great variety of used production technologies makes it difficult to find a homogenous solution to the problem of treating the wastewater containing dyes. These compounds differ in substituents and the chromophore groups which constitute their properties, such as solubility and polarity. Removal of dyes from wastewater is often associated with the need to combine several methods, including sorption, oxidation, coagulation, filtration and biodegradation [Dąbek et al., 2013].

For the removal of dyes from wastewater, the most used processes known for a long time include chlorination, ozonation, coagulation, chemical precipitation, adsorption, electrochemical processes, membrane methods and biological treatment [Babu and Murthy, 2017; Li et al. 2016; Liu et al., 2017; Khan et al., 2017; Mirzaei et al., 2017].

Chlorination of this type of wastewater is efficient only for individual groups of dyes that are destroyed under the influence of chlorine. Application of this method each time requires carrying out the experiments to determine the optimal dose of oxidant, as well as reaction time. After the chlorination process, it is necessary to neutralize wastewater [Musz-Pomorska and Widomski, 2019].

Ozonation is also a popular method for removing of sewage colour. Ozone reacts vigorously with unsaturated organic compounds, causing complete 
or partial oxidation of dye molecules. Ozonation of nitrogen dyes leads to their transformation into a biodegradable form [Quang et al., 2017].

Iron and aluminium salts are used to coagulate the wastewater containing dyes, rarely in combination with lime. The doses of coagulants depend on $\mathrm{pH}$ and type of sewage. Usually, it is between 300 and $500 \mathrm{~g} / \mathrm{m}^{3}$. The disadvantage of this method is increase in salinity and significant amounts of sludge, which account for about $5 \%$ of treated wastewater. The dyes that are not dissolved are adsorbed onto produced flocs, while dissolved dyes are not removed in this process. Coagulation with aluminium sulphate and lime is not efficient when there are direct and vat dyes in wastewater. On the other hand, a beneficial effect of cationic polyelectrolytes is observed when wastewater contains disperse dyes. Coagulation with iron(III) chloride at $\mathrm{pH}=6.5$, reduces the COD of sewage by $51.4 \%$ and absorption by $67.5 \%$. This method is of limited use, when large amounts of detergents are used in industry, e.g., textiles, which lower surface tension of water. The use of activated sludge in combination with coagulation increases the efficiency of wastewater treatment. The reduction in COD observed then is $75.4 \%$, and in absorption $74.9 \%$ [Piszcz et al., 2018].

Another and the most popular method of dye removal is adsorption. This method seems to be the most efficient due to large amount of adsorbents available on the market, which mainly include active carbons. Its unquestionable advantage is the possibility of increasing their sorption properties by means of their various surface modifications [Sarayu and Sandhya, 2012; Toutounchi et al. 2021; Verma et al. 2012]. The efficiency of this process can also be successfully increased after optimizing conditions such as temperature, $\mathrm{pH}$ and contact time. Additionally, research is constantly carried out on the application of new adsorbents for dyes removal from wastewater [Zhou et., 2019]. Selected examples of adsorption process application in removal of dyes from aqueous solutions are given in the next chapter of the work.

The pressure membrane methods (reverse osmosis and ultrafiltration) are also often used to remove dyes from wastewater. They not only enable to recover the pure water and compounds that are dissolved in wastewater, but also allow reusing these substances in technological processes. The membrane pressure processes create the opportunities for creation of closed water circuits. The use of ultra- and hyper-filtration in wastewater treatment may enable recirculation and reuse of water (hot and cold) as well as concentrated solution [Anielak, 2000].

It is also worth mentioning the biological methods that are carried out under various conditions with participation of various microorganisms. These are cost efficient and environmentally safe processes. They also offer a wide range of possibilities, especially when highly adaptable microorganisms are used. The methods of microbiological elimination of dyes are based on three main processes: biosorption, bioaccumulation and biodegradation or a combination of these mechanisms [Góralczyk et al., 2015]. Colour wastewater has a complex, often toxic and variable character; therefore, the most commonly used conventional methods reach much lower efficiency than expected. In order to improve the efficiency of these methods, research is conducted, aimed to obtain the microorganisms with a high decolorizing potential, which can be used as an auxiliary factor in already existing biological treatment systems [Zabłocka-Godlewska and Przystaś, 2019]. According to literature, the most frequently used source material in obtaining the bacteria that effectively decolourise synthetic dyes is textile sewage. It turns out that the bacteria removing of nitrogen dyes can also be obtained from other sources, e.g., compost or beech humus. Such wastewater treatment with decolorizing bacteria allows removal of dyes after only 48 hours with an efficiency exceeding 90\% [Zabłocka-Godlewska and Przystaś, 2019].

\section{Application of adsorption process for removal of dyes from aqueous solutions}

Adsorption is a process commonly used to treat wastewater from various industries. It is also effectively used to remove organic impurities, including dyes. Below are examples of applications of this process based on the latest literature data.

Synthetic nitrogen dyes make up to $65 \%$ of all dyes used in the textile industry. They are not biodegradable and therefore pose a serious threat to the natural environment. Scientific research confirms that adsorption with use of a specific mineral halloysite (HAL) is an effective method of their elimination [Sakiewicz et al., 2020].

The research on halloysite shows that the separation capabilities of synthetic nitrogen dyes depend on the initial preparation of this adsorbent (grinding, drying, etc.) and on the initial 
dye concentration in purified solution. For example, using a halloysite adsorbent ground to 0-36 $\mu \mathrm{m}$ fraction, the efficiency of AR27 nitrogen dye removal from aqueous solution was achieved in range of $21-62 \%$ and $10-50 \%$ at $56-71 \mu \mathrm{m}$ fraction. However, in the case of dried halloysite, the dye removal efficiency was $29-65 \%$ for the 0-36 $\mu \mathrm{m}$ fraction and $42-80 \%$ for $56-71 \mu \mathrm{m}$ fraction. In the case of RB5 dye, sorption efficiency was in range of $24-85 \%$ (fraction $0-36$ $\mu \mathrm{m}$ ) and $55-73 \%$ (fraction 56-71 $\mu \mathrm{m}$ ). Dried halloysite showed efficiency in the ranges of 6295\% (fraction $0-36 \mu \mathrm{m}$ ) and 69v93\% (fraction 56-71 $\mu \mathrm{m}$ ). It can be concluded that the dried halloysite adsorbent showed better adsorption capacity for both analysed nitrogen dyes. The obtained results prove the usefulness of mineral in the removal of synthetic nitrogen dyes from aqueous solutions [Sakiewicz et al., 2020].

Another interesting example is the use of cheap and widely available sorbents, which are materials of natural origin. Such sorbents include, for example, sawdust. With the use of this waste adsorbent, studies were carried out on removal of nitrogen dyes from aqueous solutions. It was then observed that adsorption was most effective in an acidic environment at $\mathrm{pH}$ 2.5. In this case, the sorption capacity of this material was about $4.70 \mu \mathrm{mol} / \mathrm{g}$. The worst results were obtained in a neutral environment with $\mathrm{pH} 7$ (about $2.60 \mu \mathrm{mol} / \mathrm{g}$ ). The course of isotherms and adsorption parameters confirmed that acidification of environment significantly increases the adsorption capacity of sawdust. Additionally, it has been proven that the increase in ionic strength of solution caused by addition of salt also positively influences the studied process. Therefore, it was concluded that sawdust is a cheap and effective adsorbent for removing dyes from aqueous solutions [Kuśmierek et al., 2020].

Porous carbon materials are very often used as adsorbents, due to their large specific surface area, large pore volume and mechanical strength. These materials are ideal for removing various types of contaminants found in water. Particularly noteworthy are mesoporous carbon materials obtained under laboratory conditions by hard or soft templating method. During their production, the following parameters are optimized: volume, pore size, specific surface area, rate of absorption kinetics or type and number of functional groups. This process improves the efficiency of tested materials in removing the harmful colour compounds present in aqueous solutions [Czubaszek and Choma, 2018].

The article describes the research on the dynamic adsorption of three dyes (methyl orange, orange II and methylene blue) from aqueous solutions on four carbon nanomaterials (rGO, AC-SDVB, OMC-PF and AC-F400). These materials were characterized by a very diverse porous structure; therefore, they showed different adsorption properties in relation to the dyes removed from aqueous solutions. In this work, the values of parameters of adsorption tests under flow conditions (initial concentration of dye solution, mass and flow rate of dye solution through the column) were determined. They made it possible to perform the dynamic adsorption studies on various adsorbents. The sorption capacity of used materials was significant, especially in the case of AC-SDVB activated carbon and reduced graphene oxide ( $\mathrm{rGO})$. The obtained values of sorption capacity were $669 \mathrm{mg} / \mathrm{g}$ for AC-SDVB and $706 \mathrm{mg} / \mathrm{g}$ for $\mathrm{rGO}$, respectively. The sorption efficiency of these carbons was significantly higher than that of AC-F400 activated carbon (355 $\mathrm{mg} / \mathrm{g}$ ) intended for adsorption from aqueous solutions. Thus, the results of the research from this article confirmed that appropriate modification of surface of carbon materials increases the efficiency of capturing various of harmful organic, water pollutants [Czubaszek and Choma, 2018].

Similar studies were carried out by the Paredes-Laverde team (2021), which used activated carbon for sorption of indigo carmine dye (IC) from both distilled water and sewage from the textile industry. This carbon was prepared from rice husk (RH) and coffee husk $(\mathrm{CH})$ using $\mathrm{ZnCl}_{2}$ as activating agent. The results showed that the dye adsorption on natural adsorbents and activated carbon was the best at $\mathrm{pH}=3.0$. Moreover, the best IC removal was achieved for the material prepared from the $\mathrm{ZnCl}_{2}$ activated coffee husk, for which the dye sorption efficiency was $42.4 \%$ for distilled water and $36.7 \%$ for textile wastewater, respectively. This result correlated well with the higher value of PZC (7.1), large specific surface area and porosity characteristics. Additionally, the dye adsorption on the $\mathrm{CH}-\mathrm{ZnCl}_{2}$ surface was improved using the smaller particle size and the optimal dose of adsorbent. Overall, it was found that the sorption properties of the studied carbons were much better than those of commercial activated carbon [Paredes-Laverde et al., 2021]. 
Another article describes the research on the possibility of using multiwall carbon nanotubes (MWNTs) to remove cationic and anionic dyes, namely acid scarlet 3R, auramine $\mathrm{O}$ yellow and crystal violet $2 \mathrm{~B}$. It was observed that the dye removal rate increased with increasing of contact time, and after 60 minutes system reached equilibrium. On the basis of the obtained results, it was found that the removal of acid scarlet $3 R$ and both cationic dyes (auramine $\mathrm{O}$ yellow and crystal violet $2 \mathrm{~B}$ ) was significantly influenced by the $\mathrm{pH}$ value. The maximum removal of all three tested dyes, was achieved in neutral (or slightly alkaline) solutions at $\mathrm{pH}=7-8$. It has also been proven that multi-walled carbon nanotubes can be successfully reused, after being regenerated, for wastewater treatment from organic dyes with efficiencies similar to those during their first use. It is economically viable. As a result, MWNTs can be considered a highly effective adsorbent for removing of various dyes from wastewater [Shabaan et al. 2020].

Other studies using excess activated sludge as a waste sorbent were carried out by the Pieczykolan and Płonka (2018). The sludge came from a municipal sewage treatment plant, adapted to remove the carbon, nitrogen and phosphorus compounds. In this study, experiments were carried out on static sorption of two types of dyes - light acid 4R (AR 18) and pure acid green V (AG 16), with use of dried excess sludge with granulation below $0.49 \mathrm{~mm}$. The experiments showed that for both AR 18 and AG 16 dyes, the highest efficiency of the sorption process was obtained at $\mathrm{pH}=2.0$. In the case of AG 16, the dye removal rate was then $56.8 \%$, and $25.9 \%$ for AR 18 dye. The use of higher $\mathrm{pH}$ resulted in a reduction in the process efficiency even to $0 \%$. The influence of contact time of sorbent with purified solutions (from 5 to 300 minutes) on the efficiency of removing both dyes was also investigated. In the case of AR 18, the most advantageous contact time of sorbent and dye was 60 minutes, while for AG 16 it was necessary to use it 3 times longer to achieve a state of equilibrium [Pieczykolan and Płonka, 2018].

The same team continued their research on removal of dyes: acid bright red 4R (AR 18) and pure acid green V (AG 16) from wastewater. In further experiments, the same dried excess sludge with a granulation below $0.49 \mathrm{~mm}$ was used, which was then subjected to chemical treatment with Fenton's reagent. Again, it was found that the most preferred adsorption $\mathrm{pH}$ was 2 for both dyes; when the $\mathrm{pH}$ was higher, the efficiency of the process decreased significantly. It was also observed that much greater amount of the AG 16 dye was adsorbed on studied material compared to the AR 18 dye. It was also proved that the modification of excess activated sludge significantly shortened effective contact time between sorbent and dyes. For AR 18, the most favourable contact time was 30 minutes, while for AG 16 it was 45 minutes [Pieczykolan et al., 2020].

\section{MATERIALS AND METHODS}

Sunflower husks (Helisnthus L.), walnut shells (Juglans regia) and rice husks (Oryza L) were used as natural sorbents. The adsorption experiments were carried out on fractions below $0.5 \mathrm{~mm}$ and on "raw" materials. Their preparation for the study consisted in their initial rinsing, drying, then shredding a part of material and sieving through a sieve. activated carbon produced by the POCH Company as well as RWAP 1013 activated carbon from coconut by EUROCARB Company were used in the experiments,. In the case of $\mathrm{POCH}$ activated carbon, grain size was below $0.5 \mathrm{~mm}$, and for RWAP 1013 was $1.70-0.425$. Working solution of dye-methylene blue (made by AVANTOR) with concentration $50 \mathrm{mg} / \mathrm{L}$ was used.

In first stage of this research, $0.5 \mathrm{~g}$ of selected sorbents were weighed with an accuracy of three decimal places. Then, the samples of these materials were placed in $250 \mathrm{~mL}$ ground-glass conical flasks. After that, $50 \mathrm{~mL}$ of working solution was poured into flasks with sorbent and they were placed on a laboratory shaker, type SK-0330 PRO, manufactured by DragonLab Instruments. The solutions were shaken for 60 minutes at $120 \mathrm{rpm}$, at a constant temperature of $298 \mathrm{~K}$. After shaking, the mixture was filtered through a hard, paper filter to remove particles. Then, the samples were taken from the filtrates for analysis on UV-VIS spectrophotometer.

The adsorption efficiency was calculated according to Eq. (1):

$$
X=\left(\frac{c_{0}-c_{k}}{c_{0}}\right) \cdot 100 \%
$$

where: $X$-adsorption efficiency (\%);

$c_{0}-$ initial dye concentration in the solution (mg/L);

$c_{k}$ - final dye concentration in the solution (mg/L). 


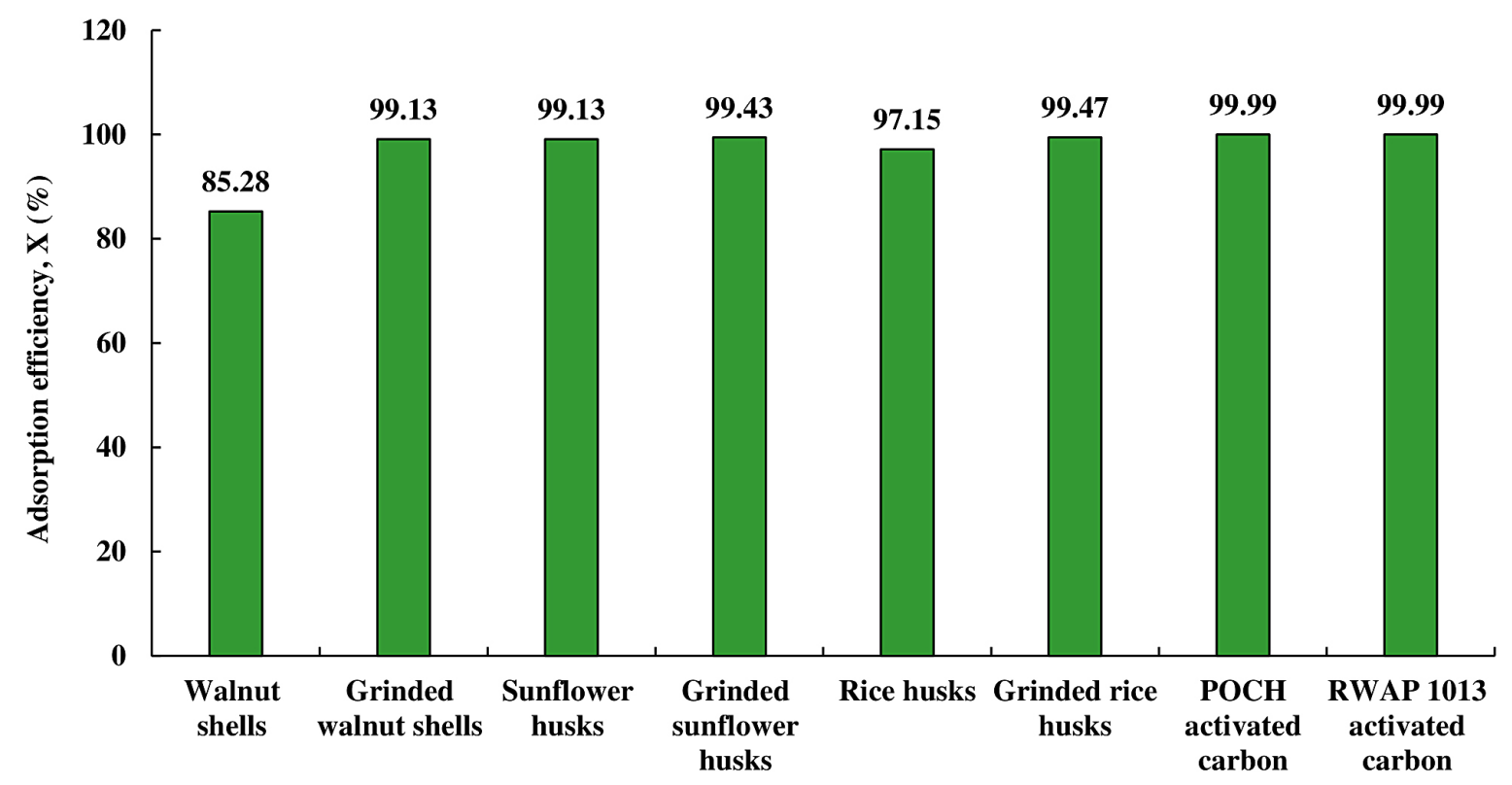

Figure 1. Comparison of adsorption results obtained for studied natural sorbents and activated carbons

Measurements of the methylene blue concentration in the studied samples were performed using UV-VIS Cadas 200 spectrophotometer made by Dr. Lange. This device was calibrated by standard curve method. All absorbance measurements were made at a wavelength of $660 \mathrm{~nm}$ in cuvettes for which the thickness of absorbing layer was 1 $\mathrm{cm}$. Additionally, before measuring, each sample was filtered using syringe filters with PTFE membrane, which have hydrophobic properties and high chemical resistance.

\section{RESULTS AND DISCUSSION}

The obtained results confirmed that natural sorbents can be successfully used to remove dyes from aqueous solutions (Fig. 1). They had high sorption efficiency close to that of activated carbons. The process efficiency for these materials was over $99 \%$. This proves their competitiveness in relation to the modified carbon adsorbents. They are usually cheap, widely available and safe materials. The possibility of managing unnecessary waste and easy biodegradation of biomass are additional advantages of this method.

A significant influence of fragmentation degree of adsorbents on the efficiency of the dye removal process was observed only in the case of walnuts. This material showed greater efficiency after grinding (by approx. 14\%). In the case of remaining adsorbents, results were similar, regardless of their fragmentation. For example, the sunflower husks, before and after grinding, removed dyes in approx. 99\%. This is a promising result. It is worth emphasizing that the production costs of ground sorbents are significant. The adsorption process itself then becomes much more expensive. Since the efficiency of some natural, non-grinded sorbents is that high, this costly stage of their preparation for use can be successfully eliminated.

\section{CONCLUSIONS}

Removal of dyes from industrial wastewater is a difficult and complex process due to its diverse chemical composition. Despite the availability of numerous physicochemical and biological methods, treatment of wastewater containing coloured compounds is still a significant problem. One of competitive solutions for the treatment of coloured wastewater is the application of adsorption based on natural sorbents.

Natural sorbents can be effectively used to remove coloured compounds from aqueous solutions. These materials are competitive with commonly used adsorbents like activated carbons. The dye sorption efficiency obtained for them reach the values of over $99 \%$, which was confirmed by the carried out research.

It is also worth paying attention to the costs of treating this type of wastewater, especially when it contains the substances resistant to degradation and toxic to microorganisms. The 
wastewater treatment is a very expensive process; therefore, the use of expensive carbon adsorbents is disadvantageous. Replacing them with equally efficient, much cheaper sorbents, like waste natural adsorbents is a better solution.

\section{REFERENCES}

1. Anielak A.M. 2000. Chemical and physicochemical wastewater treatment. Wyd. PWN, Warszawa (in Polish).

2. Babu J., Murthy Z.V.P. 2017. Treatment of textile dyes containing wastewaters with PES/PVA thin film composite nanofiltration membranes. Separation and Purification Technology, 183, 66-72.

3. Czubaszek M., Choma J. 2018. Adsorption studies of selected dyes from aqueous solutions on nanoporous carbon materials under dynamic conditions. Annual Set The Environment Protection, 3, 3-8. (in Polish).

4. Dąbek L., Ozimina E., Picheta-Oleś A. 2013. Research on removal of coloured organic compounds from textile industry wastewater. Annual Set The Environment Protection, 15, 1164-1176 (in Polish).

5. Góralczyk A., Jasińska A., Długoński J. 2016. Microbial elimination of toxic industrial dyes. Advances in Microbiology, 55(4), 424-432 (in Polish).

6. Guan Y., Rao J., Wu Y., Gao H., Liu S., Chen G., Peng F. 2020. Hemicelluloses - based magnetic aerogel as an efficient adsorbent for Congo red. International Journal of Biological Macromolecules, 155, 369-375.

7. Khan Z.U.H., Khan A., Chen Y., Khan A.U., Shah N.S., Muhammad N., Murtaza B., Tahir K., Khan F.U., Wan P. 2017. Photo catalytic applications of gold nanoparticles synthesized by green route and electrochemical degradation of phenolic Azo dyes using AuNPs/GC as modified paste electrode. Journal of Alloys and Compounds, 725, 869-876.

8. Kliś S. 2019. Application of selected chemical oxidation processes for decolorization of aqueous solutions and purification of model textile wastewater. Ph.D. Thesis. Silesian University of Technology, Gliwice (in Polish).

9. Kusumawati Samik N., Santoso A.B., Muslim S. 2020. New natural dyes development: Caesalpinia Sappan L.-Curcuma Longa blended dyes. Rasayan Journal of Chemistry, 13(2), 991-999.

10. Kuśmierek K., Gałan M., Kamiński W., Świątkowski A. 2020. Use of sawdust as a low-cost sorbent for the removal of azo dyes from water. Przemysł Chemiczny, 2, 201-205 (in Polish).

11. Kwiecień H. 2014. Chemistry and preparation of organic dyes. Wyd. Zachodniopomorski Uniwersytet Technologiczny, Szczecin (in Polish).
12. Li H., Liu S., Zhao J., Feng N. 2016. Removal of reactive dyes from wastewater assisted with kaolin clay by magnesium hydroxide coagulation process. Colloids and Surfaces A: Physicochemical and Engineering Aspects, 494, 222-227.

13. Liu M., Chen Q., Lu K., Huang W., Lü Z., Zhou C., Yu S., Gao C. 2017. High efficient removal of dyes from aqueous solution through nanofiltration using diethanolamine-modified polyamide thin-film composite membrane. Separation and Purification Technology, 173, 135-143.

14. Mirzaei N., Ghaffari H.R., Sharafi K., Velayati A., Hoseindoost G., Rezaei S., Mahvi AH, Azari A., Dindarloo K. 2017. Modified natural zeolite using ammonium quaternary based material for acid red 18 removal from aqueous solution. Journal of Environmental Chemical Engineering, 5, 3151-3160.

15. Musz-Pomorska A., Widomski M.K. 2019. Variant analysis of the chlorination efficiency of water in a selected water supply network. ECOpole'19 Conference, 9-12.10.2019, Polanica Zdrój (in Polish).

16. Okoniewska E. 2016. Removal of the Dye of Acid Bright Red 4R from Water Solutions on Activated Carbons. Engineering and Protection of Environment, 19(3), 331-340 (in Polish).

17. Paredes-Laverde M., Salamanca M., Diaz-Corrales J.D., Flórez E., Silva-Agredo J., Torres-Palma R.A. 2021. Understanding the removal of an anionic dye in textile wastewaters by adsorption on $\mathrm{ZnCl}_{2}$ activated carbons from rice and coffee husk wastes: A combined experimental and theoretical study. Journal of Environmental Chemical Engineering, 9(4), 105685.

18. Pieczykolan B., Płonka I. 2018. Application of excess activated sludge as waste sorbent for dyes removal from their aqueous solutions. Proceedings of ECOpole, 12(1), 219-227.

19. Pieczykolan B., Płonka I., Zając R. 2020. Chemically modified excessive sludge as an adsorbent of dyes. Proceedings of ECOpole, 14, 29-37.

20. Piszcz P., Jagiełło P., Głód B. 2018. Possibility of using methylene blue as a sensor to determine the total antioxidant potential by respect to hydroxyl radicals. Camera Separatoria, 1, 17-28 (in Polish).

21. Quan X., Luo D., Wu J., Li R., Cheng W., Ge S. 2017. Ozonation of acid red 18 wastewater using $\mathrm{O}_{3} / \mathrm{Ca}(\mathrm{OH})_{2}$ system in a micro bubble gas-liquid reactor. Journal of Environmental Chemical Engineering, 5, 283-291.

22. Sakiewicz P., Piotrowski K., Boryń D., Kruk M., Mścichecka J., Korus I., Barbusiński K. 2020. Use of the halloysite sorbent for the removal of the synthetic azo dyes Acid Red 27 and Reactive Black 5 from aqueous solutions. Przemysł Chemiczny, 99(8), 1142-1148 (in Polish).

23. Sarayu K., Sandhya S. 2012. Current technologies for biological treatment of textile wastewater - a 
review. Applied Biochemistry and Biotechnology, 167, 645-661.

24. Shabaan O.A., Jahin H.S., Mohamed G.G. 2020. Removal of anionic and cationic dyes from wastewater by adsorption using multiwall carbon nanotubes. Arabian Journal of Chemistry 13, 3, 4797-4810.

25. Toutounchi S., Shariati S., Mahanpoor K. 2021. Application of Magnetic ordered mesoporous carbon Nanocomposite for the Removal of Ponceau 4R Using Factorial Experimental Design. Silicon 13, 1561-1573.
26. Verma A.K., Dash R.R., Bhunia P. 2012. A review on chemical coagulation/flocculation technologies for removal of colour from textile wastewaters. Journal of Environmental Management, 93, 154-168.

27. Zabłocka-Godlewska E., Przystaś W. 2019. Obtaining of bacteria with the abilities of decolourization of azo dyes. ECOpole'19 Conference, 9-12.10.2019, Polanica Zdrój (in Polish).

28. Zhou Y., Lu J., Zhou Y., Liu Y. 2019. Recent advances for dyes removal using novel adsorbents: A review. Environmental Pollution, 252, 352-365. 